\title{
Muhasebe ve Denetim Standartlarindaki Güçlenmenin Yenilikçi İşletmelerin Büyümelerine Etkisi
}

\section{Dr. Öğr. Üyesi İsmail Elagöz ${ }^{1^{*}}$ \\ Dr. Öğr. Üyesi Ayşe Atılgan Sarıdoğan²}

Geliş tarihi: 02.09.2019

Kabul tarihi: 18.10.2019

\section{Atıf bilgisi:}

IBAD Sosyal Bilimler Dergisi

Sayı: Özel Sayı Sayfa: $678-687$

Yıl: 2019

This article was checked by Turnitin. Similarity Index 22\%

${ }^{1 *}$ Çanakkale Onsekiz Mart Üniversitesi, Türkiye, ismailelagoz@comu.edu.tr, ORCID: 0000-0003-1856-0746

2 İstanbul Arel Üniversitesi, Türkiye, ayseatilgansaridogan@arel.edu.tr, ORCID: 0000-0002-4091-9949
ÖZ

Yenilik, bugün pek çok işletmenin varlığını devam ettirebilmek ve rekabetçi olabilmek için kullandığı bir süreçtir. Ülkelerin ekonomik gelişiminde; şeffaflık, hukukun üstünlüğü yanında uluslararası muhasebe ve denetim standartlarının güçlü bir şekilde uygulanması da oldukça önemlidir. Bu çalışmada, yenilikçi işletmelerin sürdürülebilir büyümesinde önem arz eden muhasebe ve denetim standartlarının gücü, 2018 yllı verilerine göre 140 ülke için ANOVA testi ile incelenmiștir. Ampirik sonuçlara göre, muhasebe denetim standartları düzeyinin gelişmişlik düzeyine göre, yenilikçi işletmelerin büyümesi, ülke grupları için ortalamada istatistiksel olarak anlamlı farklılık göstermektedir. Muhasebe ve denetim standartları düzeyi arttıkça, yenilikçi işletmelerin büyümesi de artış göstermektedir. Sonuç olarak, işletmelerin sürdürülebilir büyümelerinde önemli bir role sahip olan muhasebe ve denetim standartlarının etkin uygulanması için gerekli politika ve stratejileri uygulamaları son derece büyük önem arz etmektedir.

Anahtar Kelimeler: Muhasebe ve Denetim Standartları, Sürdürülebilir Büyüme, ANOVA 
The Effect of Strengthening Accounting and Auditing Standards on the Growth of Innovative Companies

\author{
Assist. Prof. Dr. İsmail Elagöz ${ }^{1^{*}}$ \\ Assist. Prof. Dr. Ayşe Atılgan Sarıdoğan²
}

First received: 02.09.2019

Accepted: 18.10 .2019

\section{Citation:}

IBAD Journal of Social Sciences

Issue: Special Issue Pages: 678-687

Year: 2019

This article was checked by Turnitin. Similarity Index $22 \%$

${ }^{1 *}$ Çanakkale Onsekiz Mart University, Turkey, ismailelagoz@comu.edu.tr, ORCID: 0000-0003-1856-0746

2 İstanbul Arel University, Turkey, ayseatilgansaridogan@arel.edu.tr, ORCID: 0000-0002-4091-9949

* Corresponding Author

\begin{abstract}
Innovation is a process used by many businesses to maintain their existence and to be competitive. In the economic development of countries; transparency, the rule of law and the strong application of international accounting and auditing standards are also important. In this study, the strength of accounting and auditing standards, which are important for the sustainable growth of innovative firms, were analysed by ANOVA test for 140 countries according to 2018 data. According to the empirical results, the growth of innovative firms, according to the level of strength of the accounting and auditing standards, shows a statistically significant difference for the country groups. As the level of auditing and accounting standards increases, the growth of innovative firms also increases. Consequently, it is of utmost importance that firms implement the policies and strategies necessary for the effective implementation of accounting and auditing standards, which have an important role in their sustainable growth.
\end{abstract}

Keywords: Accounting and Auditing Standards, Sustainable Growth, ANOVA 


\section{GİRIŞ}

İşletmelerin sürdürülebilir bir şekilde büyümelerini sağlamalarında etkili çok sayıda işletme içi ve işletme dışı faktörler söz konusudur. İşletme içi faktörler arasında yer alan işletmenin sahip olduğu beşeri sermaye kaynağının yapısı, fiziki kaynaklarının yapısı, kurumsallaşma düzeyi, mali yapısı, sunduğu mal ve hizmetlerin rekabetçi özellikleri gibi pek çok faktör sürdürülebilir büyümeye etki etmektedir. İşletmenin sürdürülebilir büyümesinde etkili olan işletme dışı faktörlere; işletmenin içerisinde bulunduğu pazarın rekabet düzeyi, ekonomik piyasa gelişmişlik düzeyi ve hükümetlerin veya uluslararası kuruluşların uyguladıkları politika ve standartlar örnek olarak verilebilir.

İşletmelerin özellikle finansal durumları ile ilgili sunmuş oldukları bilginin güvenilir ve doğru bir şekilde bilgi kullanıcılarına ulaşması için uluslararası alanda uygulanan temel standartlar arasında muhasebe ve denetim standartları gelmektedir. İşletmeler tarafından sunulan finansal tabloların şeffaf, karşılaştırılabilir ve işletmenin gerçek durumunu göstermesi açısından Uluslararası Muhasebe ve Finansal Raporlama Standartları oluşturulmuştur. Bu standartlar, 1973-2001 yılları arasında Uluslararası Muhasebe Standartları Komitesi (International Accounting Standards Comittee - IASC) tarafindan Uluslararas1 Muhasebe Standartları (International Accounting Standards - IAS) olarak yayımlanmıştır. 2001 yılından itibaren ise 1973-2001 yılları arasında yayımlanan Uluslararası Muhasebe Standartları, Uluslararas1 Muhasebe Standartlar1 Kurulu (International Accounting Standards Boards - IASB) tarafindan Uluslararas1 Finansal Raporlama Standartları (International Financial Accounting Standards-IFRS) adı altında yayımlanmaya başlanmıştır (www.kgk.gov.tr).

UMS/UFRS'ye göre hazırlanan finansal tabloların bu tablolarda sunulan bilgilerin doğruluğu ve güvenilirliğinin arttırılması için mutlaka denetlenmesi gerekmektedir. Bu kapsamda Uluslararası Denetim ve Güvence Standartları Kurulu (International Auditing and Assurance Standards Board IAASB) 2003 y1lında Uluslararası Denetim ve Kalite Kontrol Standartları'nı yeniden düzenlemek amacıyla başlattığı açıklık projesini 2009 yılında tamamlamıştır. Daha sonra Uluslararası Muhasebeciler Federasyonu (International Federation of Accountants - IFAC) tarafindan bu proje el kitabı olarak yayımlanmıştır. Yayımlanan bu el kitabı ile muhasebe denetiminde uyulması gereken ilke ve esaslar ele alınmıştır (Uyar, 2015, s. 18).

Uluslararası alanda faaliyet gösteren işletmelerin esas alması gereken muhasebe ve denetim standartlarının, kullanıcıların doğru ve güvenilir bilgiye ulaşmasının yanı sıra özellikle yeni kurulan işletmelerin faaliyetlerinin ve satışlarının sürdürülebilir olmasına yardımcı olacağı düşünülmektedir. $\mathrm{Bu}$ durum göz önünde bulundurulduğunda; bu çalışmada yenilikçi işletmelerin sürdürülebilir büyümesinde önem arz eden muhasebe ve denetim standartlarının gücü, 140 ülke için 2018 yılı verileri kullanılarak ANOVA testi ile incelenmiştir.

\section{LITERATÜR}

İşletmelerin sürdürülebilir büyümeleri hem mikro hem de makro düzeyde son derece büyük önem arz etmektedir. Bu bağlamda, işletmelerin sürdürülebilir büyümelerini etkileyen işletme içi ve işletme dış1 faktörlerin titizlikle belirlenip, işletme politika ve stratejilerinin bu faktörleri en iyi yönetecek şekilde tasarlanmasi gerekmektedir.

Literatürde işletmelerin büyümesi, işletmelerin finansal performansındaki değişim çerçevesinde ele alınmakta olup bu bağlamda, işletme mali performansını etkileyen işletme içi faktörler ve işletme dış1 faktörler açıklayıcı değişkenler olarak analize katılmaktadır. Araştırmalar, işletme ve ülke gruplarının yapısı, analiz dönemi ve analiz yöntemine göre farklılaşan sonuçlar ortaya koymaktadır (Ciftci vd. 2019, Asay vd. 2018, Hamdan 2018, Kayalı ve Doğan 2018, Pradhan vd. 2018, Ünlü vd. 2017, Aytekin ve Sönmez 2016, Esendemirli ve Erdener 2016, Kaya ve Öztürk 2015, Tayeh vd. 2015, Bozkurt 2014, Ege vd. 2013, Korkmaz ve Karaca 2013, Varıc1 ve Er 2013, Yenice ve Dölen 2013, Şahin 2012, Aygün vd. 2010, Aydeniz 2009, Bowen vd. 2008, Darroch 2005, Eren vd. 2005, Vafeas 1999, Dechow 1994, Hansen and Wernerfelt 1989).

Kayalı ve Doğan (2018) çalışmalarında, Borsa İstanbul (BİST) Kurumsal Yönetim Endeksinde yer alan imalat sektöründeki işletmelerin 2012-2016 yılları arasında aldıkları kurumsal yönetim 
derecelendirme notu ile finansal başarıları arasındaki ilişkiyi incelemişlerdir. Çalışma sonucunda, işletmelerin kurumsal yönetim derecelendirme notu arttıkça iflas olasılıklarının azaldığı ve dolayısı ile finansal başarılarının arttı̆g 1 tespit edilmiştir.

Aytekin ve Sönmez (2016) yaptıkları çalışmada; ulaştırma sektöründe faaliyet gösteren ve Borsa İstanbul'da işlem gören işletmelerin 2010-2014 yıllarına ait mali tablo ve faaliyet raporlarından elde edilen veriler yardımı ile kurumsal yönetim uygulamaları ile işletme performansı arasındaki ilişkiyi ölçmeyi amaçlamışlardır. Bunun için verileri panel veri seti kullanarak regresyon analizi ile incelemişler; kurumsal yatırımcı payı, yabancı yatırımcı payı ve halka arz oranı ile aktif karlılık arasında ve yönetim kurulu üye sayısı, yabancı yatırımcı payı, nitelikli pay sahipliği oranı ile öz sermaye karlılığı arasında ilişki olduğunu belirlemişlerdir.

İşletmelerin sürdürülebilir büyümesinde etkili olan faktörler arasında mali olmayan faktörlerin literatürde önem kazandığı gözlemlenmektedir. Bu bağlamda, özellikle kurumsallaşma çerçevesindeki değişkenler işletmelerin sürdürülebilir büyümesi açısından büyük önem arz etmektedir. Muhasebe ve denetim standartları düzeyindeki iyileşmeler bir yandan işletmelerin kurumsal kaynak planlanması ve yönetiminde etkili olmakta, bu sayede verimliliğin artması, israfın azalması, maliyetlerin düşmesi, yönetim ve maliyet muhasebe uygulamalarını daha etkili uygulayabilmeleri işletmelerin kazanımlarını artırırken, diğer yandan yenilikçi işletmelerin mali performanslarının yatırımcılar tarafından daha iyi izlenmesi mümkün olmaktadır. Yenilikçi işletmelerin dış finansman kaynaklarına kavuşma imkânı arttıkça yenilikçi araştırma geliştirme ve buluşların ticarileştirilmesi süreci de daha başarılı bir şekilde yönetilerek sürdürülebilir büyüme sağlanabilmektedir.

\section{VERİ VE YÖNTEM}

Çalışmada kullanılan veriler Dünya Ekonomik Forumu'nun Küresel Rekabet Gücü 2018 yılı veri tabanından sağlanmıştır.

Çalışmada kullanılan değişkenler, ülkeler için Muhasebe ve Denetim Standartlarının Gelişmişlik Düzeyi (1-7 ölçeği, 7: En İyi) değişkeni ve Yenilikçi Firmaların Büyümesi (1-7 ölçeği, 7: En İyi)'dir. Veriler, Dünya ekonomik Forumu Yönetici anketi ile ölçülerek raporlanmıştır (Detaylı bilgi için bkz. Dünya Ekonomik Forumum Küresel Rekabet Gücü 2018).

Çalışmada ülkeler, Muhasebe ve Denetim Standartlarının Gelişmişlik Düzeyine göre düşük, orta ve yüksek olarak sınıflanarak gruplar arasında yenilikçi işletmelerin büyüme ortalamasının istatistiksel olarak farklı olup olmadığı ANOVA testi ile incelenmiştir. Değişkenlere ait düzenli karşılaştırılabilir yeterli uzunlukta zaman serisi verisinin olmamasi sebebiyle panel regresyon analizleri uygulanamamıştır.

\section{AMPÍRIK BULGULAR}

Tablo 1'de yenilikçi işletmelerin büyümesi değişkeni için tanımsal istatistikler verilmiştir. Buna göre yenilikçi işletmelerin büyüme ortalaması, muhasebe ve denetim standartlarının gelişmişlik düzeyine göre düşük olan ülkelerde 3.43, orta olan ülkelerde 3.91 ve yüksek olan ülkelerde 4.59 olarak gözlemlenmektedir.

Tablo 1. Yenilikçi İşletmelerin Büyümesi İçin Tanımsal İstatistikler

\begin{tabular}{|l|c|c|c|}
\hline \multirow{2}{*}{\multicolumn{1}{|c|}{ İstatistiksel Analiz Türleri }} & \multicolumn{3}{|c|}{$\begin{array}{c}\text { Muhasebe Denetim Standartları } \\
\text { Düzeyi }\end{array}$} \\
\cline { 2 - 4 } & Düşük & Orta & Yüksek \\
\hline Ortalama & 3.43 & 3.91 & 4.59 \\
\hline Medyan & 3.48 & 3.89 & 4.64 \\
\hline Varyans & 0.18 & 0.19 & 0.35 \\
\hline
\end{tabular}




\begin{tabular}{|l|c|c|c|}
\hline \multirow{2}{*}{\multicolumn{1}{|c|}{ İstatistiksel Analiz Türleri }} & \multicolumn{3}{|c|}{ Muhasebe Denetim Standartları } \\
& \multicolumn{2}{|c|}{ Düzeyi } \\
\cline { 2 - 4 } & Düşük & Orta & Yüksek \\
\hline Std.Sapma & 0.42 & 0.44 & 0.59 \\
\hline Minimum & 2.58 & 3.00 & 3.12 \\
\hline Maksimum & 4.21 & 4.85 & 5.83 \\
\hline Range & 1.63 & 1.85 & 2.71 \\
\hline Interquartile Range & 0.59 & 0.66 & 0.84 \\
\hline Çarpıklık & -0.26 & -0.03 & -0.15 \\
\hline Basıklık & -0.69 & -0.55 & -0.21 \\
\hline
\end{tabular}

Tablo 2'de yenilikçi işletmelerin büyümesi değişkeni için normal dağılım test sonuçları verilmiştir. Buna göre $\% 5$ anlam düzeyinde, normal dağılım geçerlidir temel hipotezi tüm alt gruplarda reddedilememektedir.

H0: Veriler normal dağılım göstermektedir.

H1: Veriler normal dă̆llım göstermemektedir.

Tablo 2. Yenilikçi İşletmelerin Büyümesi Değişkeni İçin Normal Dağılım Test Sonuçları

\begin{tabular}{|c|r|r|r|r|r|r|}
\hline \multirow{2}{*}{$\begin{array}{c}\text { Muhasebe Denetim } \\
\text { Standartları Düzeyi }\end{array}$} & \multicolumn{3}{|c|}{ Kolmogorov-Smirnova } & \multicolumn{3}{|c|}{ Shapiro-Wilk } \\
\cline { 2 - 8 } & \multicolumn{1}{|c|}{ Statistic } & \multicolumn{1}{c|}{ df } & \multicolumn{1}{c|}{ Sig. } & \multicolumn{1}{c|}{ Statistic } & \multicolumn{1}{c|}{ df } & \multicolumn{1}{c|}{ Sig. } \\
\hline Düşük &, 110 & 32 &, $200 *$ &, 962 & 32 &, 318 \\
\hline Orta &, 061 & 61 &, $200 *$ &, 988 & 61 &, 792 \\
\hline Yüksek &, 073 & 47 &, $200 *$ &, 988 & 47 &, 903 \\
\hline *. This is a lower bound of the true significance. \\
\hline a. Lilliefors Significance Correction
\end{tabular}

Tablo 3'te gruplar için Levene varyans eşitliği test sonucu verilmiştir. Buna göre, sabit varyans geçerlidir temel hipotezi \%1 anlam düzeyinde reddedilememektedir.

H0: Varyanslar eşittir.

H1: Varyanslar eşit değildir. 
Tablo 3. Levene Varyans Eşitliği Test Sonucu

\begin{tabular}{|c|c|c|c|}
\hline \multicolumn{4}{|c|}{ Yenilikçi İşletmelerin Büyümesi } \\
\hline Levene Statistic & df1 & df2 & Sig. \\
\hline 3,309 & 2 & 137 & 040 \\
\hline
\end{tabular}

Tablo 4'te ANOVA test sonucu verilmiştir. Buna göre, gruplar arasında ortalamada fark yoktur temel hipotezi $\% 5$ anlam düzeyinde reddedilmektedir. Bu bağlamda, muhasebe denetim standartları düzeyinin gelişmişlik düzeyine göre, ülke grupları için yenilikçi işletmelerin büyümesi, ortalamada istatistiksel olarak anlamlı farklılık göstermektedir.

HO: Grup ortalamaları eşittir.

H1: Grup ortalamaları eşit değildir.

Tablo 4. ANOVA Test Sonucu

\begin{tabular}{|l|r|r|r|r|r|}
\hline & Sum of Squares & df & Mean Square & \multicolumn{1}{c|}{ F } & \multicolumn{1}{c|}{ Sig. } \\
\hline Between Groups & 26,798 & 2 & 13,399 & 55,284 &, 000 \\
\hline Within Groups & 33,205 & 137 &, 242 & & \\
\hline Total & 60,003 & 139 & & & \\
\hline
\end{tabular}

Tablo 5.'te alt gruplar arasında ortalamaların ikili karşılaştırılması için test sonuçları verilmiştir. Buna göre tüm testlerde, alt grupların ikili karşılaştırmalarında gruplar arasında ortalamada fark yoktur temel hipotezi $\% 5$ anlam düzeyinde reddedilmektedir.

Tablo 5. Alt Gruplar Arasında Ortalamaların İkili Karşılaştırılması İçin Test Sonuçları

\begin{tabular}{|c|c|c|c|c|c|}
\hline \multicolumn{6}{|c|}{ Yenilikçi İşletmelerin Büyümesi } \\
\hline & $\begin{array}{c}\text { (I) Muhasebe } \\
\text { Denetim } \\
\text { Standartları Düzeyi }\end{array}$ & $\begin{array}{l}\text { (J) Muhasebe Denetim } \\
\text { Standartları Düzeyi }\end{array}$ & $\begin{array}{c}\text { Mean Difference } \\
\text { (I-J) }\end{array}$ & Std. Error & Sig. \\
\hline \multirow{6}{*}{$\begin{array}{l}\text { Tukey } \\
\text { HSD }\end{array}$} & \multirow{2}{*}{ Düşük } & Orta &,$- 47623^{*}$ & ,10746 & 000 \\
\hline & & Yüksek & $-1,15252^{*}$ &, 11283 & 000 \\
\hline & \multirow{2}{*}{ Orta } & Düşük &, $47623^{*}$ & ,10746 &, 000 \\
\hline & & Yüksek &,$- 67629^{*}$ & ,09555 &, 000 \\
\hline & \multirow{2}{*}{ Yüksek } & Düşük & $1,15252^{*}$ &, 11283 &, 000 \\
\hline & & Orta &, $67629^{*}$ & ,09555 &, 000 \\
\hline \multirow{3}{*}{ Gabriel } & \multirow{2}{*}{ Düşük } & Orta &,$- 47623^{*}$ & , 10746 &, 000 \\
\hline & & Yüksek & $-1,15252^{*}$ &, 11283 & ,000 \\
\hline & Orta & Düşük &, $47623^{*}$ & 10746 &, 000 \\
\hline
\end{tabular}




\begin{tabular}{|c|c|c|c|c|c|}
\hline \multicolumn{6}{|c|}{ Yenilikçi İşletmelerin Büyümesi } \\
\hline & $\begin{array}{c}\text { (I) Muhasebe } \\
\text { Denetim } \\
\text { Standartları Düzeyi }\end{array}$ & $\begin{array}{l}\text { (J) Muhasebe Denetim } \\
\text { Standartları Düzeyi }\end{array}$ & $\begin{array}{c}\text { Mean Difference } \\
\text { (I-J) }\end{array}$ & Std. Error & Sig. \\
\hline & & Yüksek &,$- 67629^{*}$ & ,09555 &, 000 \\
\hline & \multirow{2}{*}{ Yüksek } & Düşük & $1,15252^{*}$ &, 11283 &, 000 \\
\hline & & Orta &, $67629^{*}$ & ,09555 &, 000 \\
\hline \multirow{6}{*}{ Hochberg } & \multirow{2}{*}{ Düşük } & Orta &,$- 47623^{*}$ &, 10746 & ,000 \\
\hline & & Yüksek & $-1,15252^{*}$ &, 11283 &, 000 \\
\hline & \multirow{2}{*}{ Orta } & Düşük &, $47623^{*}$ & , 10746 &, 000 \\
\hline & & Yüksek &,$- 67629^{*}$ & ,09555 &, 000 \\
\hline & \multirow{2}{*}{ Yüksek } & Düşük & $1,15252^{*}$ & ,11283 &, 000 \\
\hline & & Orta & ,67629* & 09555 &, 000 \\
\hline
\end{tabular}

Tablo 6.'da alt grupların kümelenmesi için test sonuçları verilmiştir. Buna göre tüm testlerde alt grupların birbirinden farklı olduğu için her bir grup bağımsız bir küme oluşturmaktadır.

Tablo 6. Alt Grupların Kümelenmesi İçin Test Sonuçları

\begin{tabular}{|c|c|c|c|c|c|}
\hline & \multirow{2}{*}{$\begin{array}{l}\text { Muhasebe Denetim } \\
\text { Standartları Düzeyi }\end{array}$} & \multirow{2}{*}{$\mathbf{N}$} & \multicolumn{3}{|c|}{ Subset for alpha $=0.05$} \\
\hline & & & 1 & 2 & 3 \\
\hline \multirow{4}{*}{$\begin{array}{l}\text { Tukey } \\
\text { HSD }^{\mathbf{a}, \mathbf{b}}\end{array}$} & Düşük & 32 & 3,4334 & & \\
\hline & Orta & 61 & & 3,9097 & \\
\hline & Yüksek & 47 & & & 4,5860 \\
\hline & Sig. & & 1,000 & 1,000 & 1,000 \\
\hline \multirow{4}{*}{ Gabriel $^{\mathbf{a}, \mathbf{b}}$} & Düşük & 32 & 3,4334 & & \\
\hline & Orta & 61 & & 3,9097 & \\
\hline & Yüksek & 47 & & & 4,5860 \\
\hline & Sig. & & 1,000 & 1,000 & 1,000 \\
\hline \multirow{2}{*}{ Hochberg ${ }^{\mathrm{a}, \mathrm{b}}$} & Düşük & 32 & 3,4334 & & \\
\hline & Orta & 61 & & 3,9097 & \\
\hline
\end{tabular}




\begin{tabular}{|c|c|c|c|c|c|}
\hline & \multirow{2}{*}{$\begin{array}{l}\text { Muhasebe Denetim } \\
\text { Standartları Düzeyi }\end{array}$} & \multirow{2}{*}{$\mathbf{N}$} & \multicolumn{3}{|c|}{ Subset for alpha $=0.05$} \\
\hline & & & $\mathbf{1}$ & 2 & 3 \\
\hline & Yüksek & 47 & & & 4,5860 \\
\hline & Sig. & & 1,000 & 1,000 & 1,000 \\
\hline \multicolumn{6}{|c|}{ Means for groups in homogeneous subsets are displayed. } \\
\hline \multicolumn{6}{|c|}{ a. Uses Harmonic Mean Sample Size $=43,529$. } \\
\hline \multicolumn{6}{|c|}{$\begin{array}{l}\text { b. The group sizes are unequal. The harmonic mean of the group sizes is used. Type I error levels are } \\
\text { not guaranteed }\end{array}$} \\
\hline
\end{tabular}

Şekil 1'de muhasebe ve denetim standartları düzeyindeki değişim ve yenilikçi işletmelerin büyümesi değişkeni arasındaki ilişki verilmiştir. Buna göre muhasebe denetim standartları düzeyi arttıkça, yenilikçi işletmelerin büyümesi değişkeni de artış göstermektedir.

Şekil 1. Muhasebe ve Denetim Standartları Düzeyindeki Değişim ve Yenilikçi İşletmelerin Büyümesi Değişkeni Arasındaki İlişki

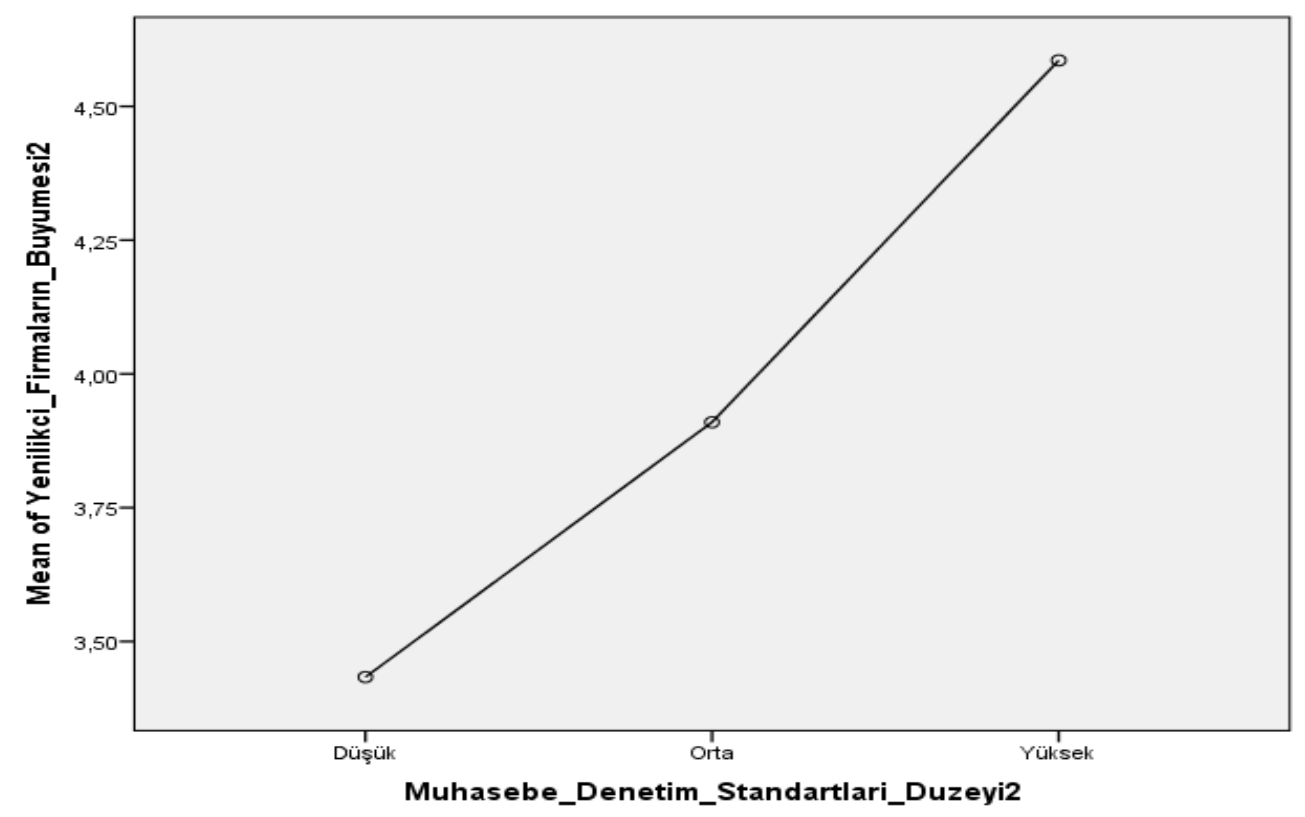

\section{SONUÇ}

Mikro düzeyde işletmelerin sürdürülebilir büyümesini etkileyen faktörlerin belirlenmesi önemlidir. Konuya ilişkin literatür incelendiğinde de işletmelerin büyümesini etkileyen faktörlerden, özellikle mali olmayan göstergelerin daha fazla önem kazanmaya başladığını görmekteyiz. Bu bağlamda, özellikle kurumsallaşma ve buna bağlı olarak muhasebe ve denetim standartlarının güçlenmesi işletmelerin sürdürülebilir büyümesi açısından kritik öneme sahip faktörler olarak karşımıza çıkmaktadır.

Çalışmada, yenilikçi işletmelerin sürdürülebilir büyümesinde önem arz eden muhasebe ve denetim standartlarının gücü, 2018 y1lı verilerine göre 140 ülke için ANOVA testi ile incelenmiştir. Ampirik sonuçlara göre, muhasebe denetim standartları düzeyinin gelişmişlik düzeyine göre, yenilikçi işletmelerin büyümesi, ülke grupları için ortalamada istatistiksel olarak anlamlı farklılık göstermektedir. Muhasebe denetim standartları düzeyi arttıkça, yenilikçi işletmelerin büyümesi de artış göstermektedir. Sonuç olarak işletmelerin, sürdürülebilir büyümelerinde önemli bir role sahip 
olan muhasebe ve denetim standartlarının etkin uygulanması için gerekli politika ve stratejileri uygulamaları son derece büyük önem arz etmektedir.

\section{KAYNAKÇA}

Asay, H. S., Libby, R. ve Rennekamp, K. (2018). Firm performance, reporting goals, and language choices in narrative disclosures. Journal Of Accounting And Economics, 65(2-3), 380-398.

Aydeniz, E. (2009). Makroekonomik göstergelerin firmaların finansal performans ölçütleri üzerindeki etkisinin ölçülmesine yönelik bir araştırma: IMKB'ye kote gıda ve içecek işletmeleri üzerine bir uygulama. Marmara Üniversitesi İktisadi ve İdari Bilimler Dergisi, 27(2), 263-278.

Aygün, M., Süleyman, İ. Ç. ve Sayın, C. (2010). Yönetim kurulu büyüklüğünü belirleyen faktörler ve yönetim kurulu büyüklüğü ile firma performansı arasındaki ilişki: Türk sermaye piyasası üzerine bir inceleme. Gaziantep University Journal Of Social Sciences, 10(1), 77-92.

Aytekin, M. ve Sönmez, A. R. (2016). Kurumsal yönetim uygulamalarının firma performans1 üzerine etkisi. Türk Sosyal Bilimler Araştırmaları Dergisi, 1(2), 32-41.

Bowen, R. M., Rajgopal, S. ve Venkatachalam, M. (2008). Accounting discretion, corporate governance, and firm performance. Contemporary Accounting Research, 25(2), 351-405.

Bozkurt, O. (2014). Mükellef firmanın iç muhasebe kontrol sistemi, firma büyüklüğü ve ününün bağımsız muhasebeci geliri ve hizmet performansı üzerine etkisi. Uluslararası Yönetim İktisat ve İşletme Dergisi, 10(21), 65-86.

Ciftci, I., Tatoglu, E., Wood, G., Demirbag, M. ve Zaim, S. (2019). Corporate governance and firm performance in emerging markets: evidence from Turkey. International Business Review, 28(1), 90-103.

Darroch, J. (2005). Knowledge management, innovation and firm performance. Journal Of Knowledge Management, 9(3), 101-115.

Dechow, P. M. (1994). Accounting earnings and cash flows as measures of firm performance: the role of accounting accruals. Journal Of Accounting And Economics, 18(1), 3-42.

Ege, İ., Topaloğlu, E. E. ve Özyamanoğlu, M. (2013). Finansal performans ile kurumsal yönetim notları arasındaki ilişki: BİST üzerine bir uygulama. Akademik Araştırmalar ve Çalışmalar Dergisi, 5 (9).

Eren, E., Alpkan, L. ve Erol, Y. (2005). Temel fonksiyonel yeteneklerin firmanın yenilik ve finansal performansına etkileri. İstanbul Ticaret Üniversitesi Sosyal Bilimler Dergisi, 4(7), 201-224.

Esendemirli, E., Acar, E. (2016). Finansal performans ve kurumsal yönetim derecelendirme notlar1: Borsa İstanbul kurumsal yönetim endeksi 2013-2014 yılları karşılaştırması. World Of Accounting Science, Special İssue(18), 625-671.

Hamdan, A. (2018). Intellectual capital and firm performance: differentiating between accounting-based and market-based performance. International Journal Of Islamic And Middle Eastern Finance and Management, 11(1), 139-151.

Hansen, G. S. ve Wernerfelt, B. (1989). Determinants of firm performance: the relative importance of economic and organizational factors. Strategic Management Journal, 10(5), 399-411.

Кати Gӧzetim Kurumu. $23 \quad$ Ağustos 2019 tarihinde https://www.kgk.gov.tr/DynamicContentDetail/6649/UMS/UFRS-nedir? adresinden erişildi.

Kaya, A. ve Öztürk, M. (2015). Muhasebe kârları ile hisse senedi fiyatları arasındaki ilişki: BİST firmaları üzerine bir uygulama. Muhasebe ve Finansman Dergisi, (67), 37-54.

Kayalı, N. ve Doğan, İ. (2018). Kurumsal yönetim derecelendirme notu ile işletmelerin finansal başarıları arasındaki ilişkinin incelenmesi. Muhasebe ve Finansman Dergisi, (78), 111-124. 
Korkmaz, Ö. ve Karaca, S. S. (2013). Firma performansını etkileyen faktörler ve Türkiye örneği. Ege Akademik Bakış, 13(2), 169.

Pradhan, D., Swain, P. K. ve Dash, M. (2018). Effect of management accounting techniques on supply chain and firm performance: an empirical study. International Journal Of Mechanical Engineering And Technology, 9(5), 1049-1057.

Şahin, O. (2012). KOBI’lerde finansal performansı belirleyen faktörler. Uluslararası Yönetim İktisat ve İsletme Dergisi, 7(14), 183-200.

Tayeh, M., Al-Jarrah, I. M. ve Tarhini, A. (2015). Accounting vs. market-based measures of firm performance related to information technology investments. International Review Of Social Sciences And Humanities, 9(1), 129-145.

Uyar, S. (2015). Denetim standartlarına göre sinirli bağımsız denetim (finansal tabloların gözden geçirilmesi). Mali Çözüm Dergisi, 130, 15-39.

Ünlü, U., Yalçın, N. ve Yağlı, İ. (2017). Kurumsal yönetim ve firma performansı: TOPSIS yöntemi ile BIST 30 firmaları üzerine bir uygulama. Dokuz Eylül Üniversitesi Sosyal Bilimler Enstitüsü Dergisi, 19(1), 63-81.

Vafeas, N. (1999). Board meeting frequency and firm performance. Journal Of Financial Economics, 53(1), 113-142.

Varıcı, İ. ve Er, B. (2013). Muhasebe manipülasyonu ve firma performansı ilişkisi: İMKB uygulaması. Ege Akademik Bakış, 13(1), 43.

Yenice, S. ve Dölen, T. (2013). İMKB'de işlem gören firmaların kurumsal yönetim ilkelerine uyumunun firma değeri üzerindeki etkisi. Uluslararası Yönetim Ikktisat ve Işsletme Dergisi, 9(19), 199-213. 